\title{
A study of hotel sector efficiency in the Canary Islands
}

Francisco José Ledesma Rodríguez

Rosa $\mathrm{M}^{\mathrm{a}}$ Lorenzo Alegría

Universidad de La Laguna, Tenerife, Spain

Received30April2019

\author{
Raquel Martín Rivero \\ Universidad de La Laguna, Tenerife, Spain
}

\begin{abstract}
This research focuses on the analysis of the efficiency of hotel supply in the Canary Islands. To do this, data on tourist accommodation from an exhaustive official survey of the hotel sector are used for the years 2010 and 2015. A production frontier is calculated by means of Data Envelopment Analysis (DEA), both from a single-product and multi-product perspective. This allows an estimation of the technical and scale efficiencies in the Canary Island hotel sector and technical efficiency scores for each hotel. Also, a simple descriptive analysis of explanatory variables of inefficiency is carried out: size, quality and location. Results suggest that there is certainly room for improvement hotels located in the Canary Islands in terms of technical efficiency. The smallest and the largest hotels achieve the highest levels of technical efficiency, highest stars hotels obtain the lowest levels of efficiency and hotels located in tourist municipalities present higher technical efficiency than those situated in the islands' capitals.
\end{abstract}

Keywords: Hotel supply, production frontier, DEA.

Paper type: Research paper

\section{Introducción}

The relevance of the tourism sector in the Canary Islands is well recognized. It ranks as the second Spanish region with most tourist arrivals, exceeding 14 million tourists in 2017. Furthermore, tourism's contribution to the islands' GDP reached $35.2 \%$, while its share in total employment was $40.3 \%$ (Exceltur and Gobierno de Canarias, 2018). A noteworthy feature of the Canary Islands as a tourist destination is its low seasonality compared to other European tourist regions (Duro, 2016). Journal of Tourism Analysis:
Revista de Análisis Turístico Vol. 28 No. 1, Año 2021 pp. 1-17

(C) Francisco José Ledesma Rodríguez, Rosa $\mathrm{M}^{\mathrm{a}}$ Lorenzo Alegría and Raquel Martín Rivero. Published in Journal of Tourism Analysis: Revista de Análisis Turístico. This article is published under the Creative Commons Attribution (CC BY 4.0) license. Anyone may reproduce, distribute, translate and create derivative works of this article (for both commercial and non-commercial purposes), subject to full attribution to the original publication and authors. The full terms of this license may be seen at http://creativecommons.org/licences/by/4.0/ legalcode 
JTA

28.1

As for accommodation structure, the Canary Islands offer 244,657 hotel beds (ISTAC, 2016a). It is worth noting that the islands' hotel supply represents a $12 \%$ share of the total Spanish hotel supply.

In spite of these figures, the literature has paid little attention to the study of the accommodation supply in this important destination of the sun-and-sand segment of the European tourism market. This lack is even more evident in the analysis of its efficiency. To our knowledge, only Pérez and Acosta (2007) have estimated a cost frontier for a set of accommodation firms located on the Island of Gran Canaria. In this sense, it is of interest to carry out a more detailed and widespread analysis of the main characteristics of the islands' hotel supply and, particularly, the estimation of its efficiency and its main causes.

In this research, the DEA method is used to estimate a measure of technical efficiency for the hotel sector in the Canary Islands using data from an official census of the ISTAC (Instituto Canario de Estadística). The majority of empirical papers on hotel sector efficiency have been conditioned by the availability of data. Some empirical works use extensive accounting databases, e.g. SABI, aida and AMADEUS. These extensive datasets do not allow to study hotel chains presenting consolidated accounts in their country or region of origin (for instance, Pérez-Rodríguez and Acosta-González, 2007; Bernini and Guizzardi, 2010). In the case of the Canary Islands this is critical given that $65 \%$ of beds are supplied by hotels belonging to chains. In this paper, the database used considers both hotels affiliated and nonaffiliated to chains.

The contribution of this paper is threefold: (i) a production frontier using a nonparametric approach (DEA) for hotel supply is estimated for the case of the Canary Islands, both with a single-product and a multi-product perspective, (ii) the efficiency analysis considers all hotels operating in the Canary Islands and, as a consequence, accurate measures of technical inefficiency are obtained, and (iii) a simple descriptive analysis of explanatory variables of inefficiency is carried out. These contributions are interesting not only as relevant information for hotel management, but also for the public sector supervising and promoting tourism activity.

The paper is organized as follows. Second section describes DEA methodology followed in this research. Third section presents the database used in this study. Fourth section shows the results from DEA for both, the single-product case and the multi-product case. Finally, last section draws some conclusions.

\section{State of the art}

Texto. The concept of efficiency and its application to explain and improve the performance of firms has received much effort by academics and practitioners. Previous studies have extensively explored this issue by mainly focusing on the concept of technical efficiency.

As known, technical efficiency refers to the ability of an organization, a hotel, to minimize used resources in order to get an output given. Technical efficiency was defined by Farrell (1957), from previous works of Debreu (1951) and Koopmans (1951).

Furthermore, there are efficiency measures based in costs and benefits. So, cost and profit efficiencies are measures based on theoretical cost and profit functions, respectively. The cost efficiency is related to the goal of minimizing payments for inputs, while the profit efficiency addresses the objective of maximizing profits. 
The technical efficiency is commonly estimated following two main approaches: Data Envelopment Analysis (DEA) and Stochastic Frontier Approach (SFA). DEA involves linear programming methods to approximate a non-parametric piecewise frontier from data. It was proposed by Charnes et al. (1978), based on the framework provided by Farrell (1957), assuming constant returns to scale (DEA CRS). The more flexible model is proposed by Banker et al. (1984) allowing variable returns to scale (DEA VRS).

As mentioned above, the concept of technical efficiency refers to the ability of a firm in order to maximize output with available resources. In an empirical approach, the DEA method determines the decision making units (DMUs) located on the production function frontier by using data of production factors and outputs. Furthermore, DEA provides an indicator of technical efficiency for each DMU, measured as the distance to the efficient frontier.

The use of the DEA methodology provides an estimation of two indicators, i.e. technical efficiency and scale efficiency. Following Coelli (1996), technical efficiency means the minimization of quantities of inputs to obtain a certain output, while scale efficiency measures if the DMUs, that is, hotels, are operating at the optimal scale. Both indicators may take values between 0 and 1 . A value of 1 for the technical efficiency means that hotel is in the efficient frontier. A value of 1 in the case of the scale efficiency suggests that hotel is at the optimal scale.

Figure 1.- DEA CRS vs DEA VRS.

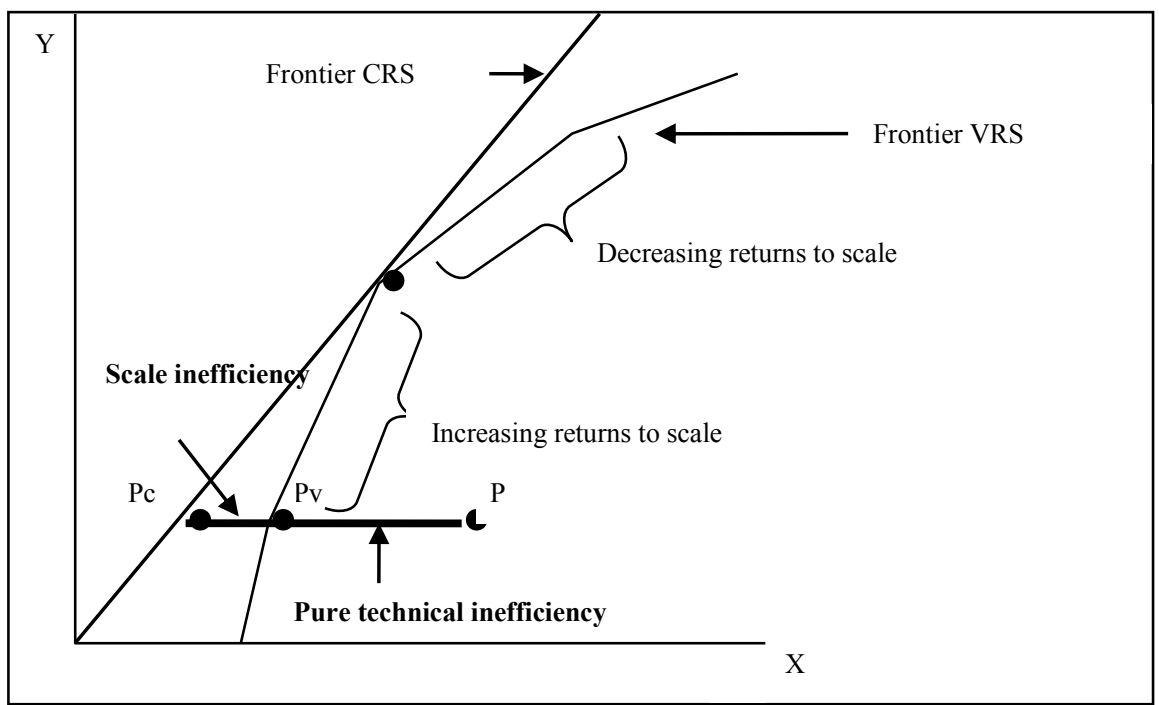


JTA

28.1

As shown in Figure 1, DEA CRS approximates a linear efficient frontier, whereas DEA VRS draws a concave efficient frontier. DMUs on the right of the frontier, such as $\mathrm{P}$, present two causes of inefficiency: scale inefficiency represented by the distance PvPc, and pure technical inefficiency measured by the distance PvP. Firms on the concave efficient frontier are technical efficient but they are not operating at the optimal scale.

DEA has been used extensively in order to analyze efficiency in many economic sectors and research fields (Cooper et al., 1999).

A second perspective has been used in order to estimate technical efficiency, i.e., the Stochastic Frontier Approach (SFA) (Charnes et al, 1978; Aigner et al. 1977; Meeusen and van den Broeck, 1977). The SFA model is a parametric approach assuming the stochastic nature of the production function, as well as a compound error. This error term includes a standard statistical error and a term measuring technical inefficiency.

The main advantage of DEA with respect to SFA is that it does not require functional specification for production function and also that it does not assume a specific distribution for the inefficiency term. Furthermore, this non-parametric approach addresses the study of efficiency in a multi-product context in a very simple way.

Also for the tourist sector an incipient literature has drawn attention to the estimation of efficiency, also in hotel sector (Assaf and Josiassen, 2016; Assaf and Tsionas, 2018). As pointed out by González et al. (2015), the hotel sector is especially relevant due to the specific features of its management: the limits to modifying the size of the hotel and the properties of non-separability, intangibility, heterogeneity, simultaneity and perishability. Since these particular characteristics conditioning the efficiency management, the estimation of the levels of technical inefficiency in the hotel sector becomes a research area of interest.

Although the literature on technical efficiency is very extensive and with applications to many sectors, it has received less attention in the case of the hotel sector. Some examples are Anderson et al. (1999), Chen (2007), Barros (2004), Barros and Dieke (2008), Kim (2011), and Sáez-Fernández et al. (2020). Furthermore, some empirical work on cost and profit efficiency has put the spotlight on the analysis of cost and benefit efficiency in the hotel sector. See, for instance, Arbelo-Pérez et al. (2017), Assaf and Jossiasen (2016), and Barros (2004).

Assaf and Josiassen (2016) present a review of the literature focused on parametric and non-parametric techniques applied to tourism activities. Among the contributions to this field, we can highlight Johns, Howcroft and Drake (1997) analyzing technical efficiency for a sample of 15 hotels located in the UK, Anderson et al (1999) for 48 hotels in the US, Hwang and Chang (2003), Wang et al (2006) and Chiang, Tsai and Wang (2004) for different samples of the hotel sector of Taiwan, Sigala et al (2004) for a sample of 933 -star hotels of the UK, Barros (2005) and Barros and Mascarenhas (2005) for hotels located in Portugal, Sanjeev (2007) for a sample of 68 hotels in India and Pulina and Santoni (2018) for hotels in Italy.

For the case of Spain, Arbelo et al (2017) used a stochastic frontier model to estimate cost efficiency in the hotel industry in Spain between 2008 and 2012, for a sample of 231 hotels. Also, Benito et al (2014) ran a two-stage DEA for a sample of Spanish hotels. Fernández and Becerra (2015) applied DEA for 166 hotels over the period 2000-2009. Such and Mendieta (2015) also used DEA method for 424 hotels (excluding Canary Islands from the analysis) and the period 2004-2006. De Jorge and Suárez (2014) and Parte-Esteban and Alberca-Oliver (2015) applied a semiparametric two-stage approach combining DEA and a stochastic model to explore the determinants of efficiency. 
For the case of Spain, Arbelo et al (2017) used a stochastic frontier model to estimate cost efficiency in the hotel industry in Spain between 2008 and 2012, for a sample of 231 hotels. Also, Benito et al (2014) ran a two-stage DEA for a sample of Spanish hotels. Fernández and Becerra (2015) applied DEA for 166 hotels over the period 2000-2009. Such and Mendieta (2015) also used DEA method for 424 hotels (excluding Canary Islands from the analysis) and the period 2004-2006. De Jorge and Suárez (2014) and Parte-Esteban and Alberca-Oliver (2015) applied a semiparametric two-stage approach combining DEA and a stochastic model to explore the determinants of efficiency.

Recent advances addressing the heterogeneity in a more flexible way incorporate Bayesian methods. In practice, firms, as hotels, have different technologies, and this methodology allows to separate firm-specific inefficiencies from potential technological heterogeneity across hotels. See, for instance, Deng et al (2019) for a cross-sectional data set of Spanish hotel chains, Assaf and Tsionas (2018) for the case of the accommodation sector in a very heterogeneous sample of international hotels and Arbelo-Pérez et al (2020).

It is surprising the lack of references estimating efficiency for the case of the hotel sector of the Canary Islands, given that Canary Islands are a main tourist destination in the European sun-and-beach tourism market. As mentioned in the introduction, for the case of the Canary Islands only Pérez and Acosta (2007) estimated a cost frontier for a set of accommodation firms located on the Island of Gran Canaria.

This paper estimates a production frontier for hotel sector of Canary Islands using a DEA approach and also explores several determinants of technical efficiency: size, quality and location. A look at the literature allows us to distinguish between external and internal factors affecting technical efficiency (Badunenko et al, 2006). Among the external factors, the location is commonly identified as a determinant of efficiency (Lado-Sestayo and Fernández-Castro, 2019). Therefore, regional differences in characteristics of labor force, urban location and industrial structure are recognized as factors conditioning efficiency (Beeson and Husted, 1989). Similarly, Barros (2005), Wang et al (2006), Bernini and Guizzardi (2010), and Badunenko et al (2006) focus on location as an empirical determinant of efficiency. In particular, Badunenko et al (2006) conclude that location explains about $10 \%$ of variation in technical efficiency.

Among the internal factors, the size of firms is recognized as a factor explaining technical efficiency (Caves and Barton, 1990; Gumbau-Albert and Maudos, 2002; and Badunenko et al, 2006). According to size, firms may differ in capital-labour ratio, wages, and capital costs. These differences may contribute to explaining differences in technical and scale efficiencies. In this way, Caves and Barton (1990) find slightly higher technical efficiency in larger firms than in smaller ones for a case study of the U.S. manufacturing sector. Badunenko et al (2006) find that small firms are more efficient than large ones and that firm size is the second most relevant factor that influences efficiency. Finally, the quality of service is another internal factor that has been included as a determinant of efficiency. In this sense, Yang and Zeng (2014) find the expected trade-off between quality and efficiency for the case of public and private hospitals of China.

\section{Data}

This paper focuses on the study of the technical and scale efficiencies of hotels located in the Canary Islands for the years 2010 and 2015, where a complete dataset was available. Data used in this research was obtained from Encuesta de Alojamiento Turístico (EAT) and Encuesta de Gasto Turístico (EGT) of the ISTAC, i.e. the Office for Regional Statistics of the Canary Islands. These data are official and cover the whole of the hotel sector (626 hotels in 2015 and 611 hotels in 2010). This database was filtered in order to eliminate hotels with a zero-value for some input or output2. In addition, 1-star hotels were eliminated from the database, since they are commonly small family businesses with the participation of non-paid labor and where management goals could be different from the pure minimization of costs (Bernini and Guizzardi, 2010). 
We carried out two approaches on the production frontier, i.e. a single-product analysis and a multi-product analysis. As output variable the overnight stays is chosen since it is an accurate variable to approximate the volume of output in a production frontier for the hotel sector3. For the multi-product case, a set of five outputs are considered, the overnight stays accounting for different accommodation regimes: only accommodation, accommodation+breakfast, half-board, full-board, and all-inclusive4. As input variables, labor and capacity (measured by the number of beds) are used.

The sample sizes for the single-product analysis were 502 and 519 hotels in 2010 and 2015, respectively. For the multi-product analysis, the sample sizes were notably reduced given that the procedure requires non-zero quantities for the five outputs. So they were 113 and 180 hotels, for 2010 and 2015, respectively.

Table 1. Descriptive statistics. 2010 and 2015.

\begin{tabular}{|c|c|c|c|c|c|}
\hline & Mean & Median & Maximun & Minimun & SD \\
\hline Total overnight stays & 117281,03 & 94119 & 764509 & 413 & 106571,86 \\
\hline Only accommodation & 17872,7 & 10170,9 & 245446,3 & 1106,4 & 25584,5 \\
\hline Accommodation and breakfast & 20769,6 & 13729,2 & 125323,7 & 362,5 & 21869,6 \\
\hline Half-board & 70690,1 & 53358,9 & 568880,8 & 443,9 & 70595,4 \\
\hline Full-board & 11595,2 & 7739,3 & 114081,1 & 195,1 & 12324,4 \\
\hline All-inclusive & 61545,7 & 38488,9 & 329578,0 & 221,3 & 65777,5 \\
\hline Labour & 79,78 & 60,00 & 589,00 & 1,00 & 79,61 \\
\hline Size (beds) & 469,45 & 415,00 & 2157,00 & 5,00 & 372,05 \\
\hline Stars & 3,48 & 4 & 5 & 2 & 0,84 \\
\hline Correlation matrix & Overnight stays & $\begin{array}{l}\text { Size } \\
\text { (beds) }\end{array}$ & Labour & Stars & \\
\hline Overnight stays & 1 & & & & \\
\hline Size (beds) & 0,9228 & 1 & & & \\
\hline Labour & 0,8291 & 0,8075 & 1 & & \\
\hline Stars & 0,3697 & 0,3822 & 0,5110 & 1 & \\
\hline
\end{tabular}

Table 1 shows descriptive statistics used in the empirical analysis. As mentioned in Section 1 , it is noticeable the large size of hotels in the Canary Islands, with an average about 470 beds per hotel. Furthermore, the median (and the mode) of the number of stars is four, suggesting a relatively high quality of hotel supply in this destination. Also, full-board seems to be reducing its weight among accommodation regimes in favor of all-inclusive. Finally, correlation coefficients seem to give support to the analysis of a production function in the next section.

As mentioned before, one main advantage of our research is the large dataset used that includes all the hotels operating in the Canary Islands. This means the results from DEA analysis are more reliable. In fact, the large dataset avoids a common drawback of previous works using small samples, i.e. the high probability of obtaining firms on the efficient frontier (Banker, 1993). As mentioned in the introduction, most empirical research uses extensive accounting databases (e.g. SABI for Spain, aida for Italy, and AMADEUS) with consolidated accounts, which makes it more difficult to study hotels belonging to a chain. Our work incorporates hotels affiliated to chains. 
This is critical for the case study of the Canary Islands, since $65 \%$ of beds are offered by hotels that are a part of a chain. Also accounting databases classify enterprises by economic activity in a way which does not fit research needs, mixing quite different types of accommodation.

\section{Results}

In this section, the results of the DEA analysis to calculate efficiency are presented. Specifically, four efficient frontiers are estimated for the years 2010 and 2015, by using both single-product and multi-product perspectives.

A first decision in DEA analysis is about the returns to scale assumed. CRS is too restrictive given that it requires that all firms are operating at the optimal scale (Assaf and Josiassen, 2016). If notable differences between VRS and CRS are found, it suggests the presence of variable returns of scale and the relevance of the VRS approach.

A second relevant decision is whether the approach must be input-oriented or outputoriented. As pointed out by Assaf and Josiassen (2016), output-oriented may be suitable for firms operating in highly competitive markets. In the case of hotel services, the intensity of the use of product differentiation strategies, as well as the number of suppliers and hotel size suggest the output-oriented may be an inappropriate approach. In addition, the capacity of hotels is limited, and it is difficult to increase output (overnight stays) notably in the short term. For these reasons, our analysis is input-orientated to measure technical efficiency.

\subsection{Single-product analysis}

Table 2 presents the average efficiency indicators from the DEA approach for the single-product analysis, for years 2010 and 2015.

Table 2. DEA Efficiency Scores for hotels in Canary Islands. Single-product analysis.

\begin{tabular}{lcccc}
\hline & Hotels & $\begin{array}{c}\text { Average technical } \\
\text { efficiency CRS }\end{array}$ & $\begin{array}{c}\text { Average technical } \\
\text { efficiency VRS }\end{array}$ & $\begin{array}{c}\text { Efficient hotels } \\
\text { VRS } \geq 0.9\end{array}$ \\
\hline 2010 & 502 & $0.494(0.171)$ & $0.552(0.172)$ & 21 \\
2015 & 519 & $0.564(0.171)$ & $0.609(0166)$ & 28 \\
\hline
\end{tabular}

Note: standard deviation of indicators appears in brackets. A threshold of 0.9 is taken to define technically efficient hotels only with an illustrative goal.

As can be observed, VRS indicators are different from CRS indicators suggesting the presence of scale inefficiency. As a consequence, this research focuses on a VRS approach. Scale inefficiency may be explained by the presence of imperfect competition and financial constraints (Coelli, 1996).

The average technical efficiency under VRS is equal to 0.55 in 2010, and 0.6 in 2015. This implies that hotels in the Canary Islands are not on the efficiency frontier and inputs could be reduced, on average, about $45 \%$ without reducing their current output level in year 2010. In 2015, this reduction in inputs would be about $40 \%$. These results suggest that there remains scope for improvement of technical efficiency in the Canary Island hotel sector. As a consequence, this evidence can be of interest given that more effort must be put in the effective management of hotels and perhaps in the design of public policy oriented to the hotel sector.

For its part, the average scale efficiency is about 0.9. This high level of scale efficiency may be explained by the high average size of hotels. According to the Instituto Nacional de Estadística (INE), the average number of beds per hotel in the whole national territory was 84 beds in 2010 and 88 in 2015 while in the Canary Islands it was 386 beds in 2010 and 390 in 2015. So the average hotel size in the Canary Islands was four times greater than hotels in Spain. 
JTA

\subsection{Multi-product analysis}

For the multi-product study, five outputs (overnight stays) are considered: only accommodation, accommodation and breakfast, half-board, full-board, and allinclusive. In this sense, our analysis recognizes the relevance of accommodation regimes in terms of the efficient management of hotels.

Output variables were calculated from frequencies of accommodation regimes (EGT database) and overnight stays for each hotel (EAT database). Given the characteristics of DEA method mentioned in section of methodology, the samples analyzed only considered hotels offering the five regimes and using two inputs. Multi-product approach assumes that inputs are shared for the production of the five outputs in presence of scope economies.

Table 3 presents aggregate results for the multi-product analysis. As can be observed, calculated indicators highlight that the use of inputs could be reduced without reducing outputs by around $12 \%$ in 2010 and $16 \%$ in 2015 . Note that the results of this analysis cannot be compared to those obtained from the single-product approach. The sample used in the multi-product analysis is different since (i) outputs are calculated not only from the EAT database but also from the EGT database, including fewer hotels, (ii) the mentioned characteristics of the DEA method, which additionally excludes hotels with a null value of some product, and (iii) in the DEA method the probability of being efficient naturally increases with the number of outputs considered (Coelli, 1996).

Table 3. DEA Efficiency Scores for hotels in Canary Islands. Multi-product analysis.

\begin{tabular}{ccccc}
\hline Year & Hotels & $\begin{array}{c}\text { Efficient hotels } \\
\text { VRS } \geq 0.9\end{array}$ & $\begin{array}{c}\text { Average technical } \\
\text { efficiency }\end{array}$ & $\begin{array}{c}\text { Average scale } \\
\text { efficiency }\end{array}$ \\
\hline 2010 & 113 & 61 & $0.8790(0.129)$ & $0.9635(0.060)$ \\
2015 & 180 & 77 & $0.8447(0.143)$ & $0.9509(0.089)$ \\
\hline $\begin{array}{l}\text { Note: standard deviation of indicators appears in brackets. A threshold of } 0.9 \text { is taken to define } \\
\text { technically efficient hotels only with an illustrative goal. }\end{array}$
\end{tabular}

\section{Discussion}

In this section a discussion of results is presented, focusing on the exploration of the determinants of efficiency in the hotel sector of the Canary Islands.

Among the determinants explored in the empirical literature on efficiency, and given the availability of data, this research explores three potential determinants: size, category and location of hotels.

Regarding hotel size, previous evidence is mixed. On the one hand, Barros and Dieke (2008) conclude the largest hotels are the most technically efficient, and they operate close to the optimal scale. On the other hand, Chen (2007) and Hwang and Chang (2003) do not find differences in efficiency between small and large hotels. Furthermore, De Jorge and Suárez (2014) estimate a U-shaped relationship between technical efficiency and hotel size. Therefore, the relation between efficiency and size is still in discussion (Assaf et al., 2010).

A simple descriptive analysis of the relationship between size and efficiency indicators for a single-product perspective is presented in Table 4 and Figure 2.

Table 4 presents results attending to the number of beds as size variable distributed by quartiles. 
Table 4. Single-product analysis of efficiency by size for 2010 and 2015.

\begin{tabular}{|c|c|c|c|c|c|}
\hline Number of beds & Number of hotels & $\begin{array}{c}\text { Number of efficient } \\
\text { hotels VRS } \geq 0.9\end{array}$ & $\begin{array}{l}\text { Average } \\
\text { technical } \\
\text { efficiency }\end{array}$ & $\begin{array}{c}\text { Average scale } \\
\text { efficiency }\end{array}$ & $\begin{array}{l}\text { sector } \\
\text { efficiency in }\end{array}$ \\
\hline \multicolumn{6}{|l|}{2010} \\
\hline $0-150$ & 126 & 14 & $0.527(0.212)$ & $0.703(0.222)$ & Islands \\
\hline $151-414$ & 125 & 0 & $0.496(0.144)$ & $0.953(0.053)$ & \\
\hline $415-694$ & 126 & 4 & $0.574(0.163)$ & $0.988(0.018)$ & \\
\hline$>694$ & 125 & 3 & $0.609(0.137)$ & $0.969(0.043)$ & 9 \\
\hline \multicolumn{6}{|l|}{2015} \\
\hline $0-168$ & 130 & 13 & $0.586(0.190)$ & $0.773(0.227)$ & \\
\hline $169-416$ & 132 & 1 & $0.570(0.157)$ & $0.975(0.021)$ & \\
\hline $417-700$ & 130 & 3 & $0.624(0.146)$ & $0.994(0.007)$ & \\
\hline$>700$ & 127 & 10 & $0.659(0.153)$ & $0.975(0.055)$ & \\
\hline
\end{tabular}

Note: standard deviation of indicators appears in brackets. As an illustrative goal, a threshold of 0.9 is taken to define technically efficient hotels.

Figure 2. Relationship between size, technical efficiency and scale efficiency. 2010-2015. Single-product analysis.
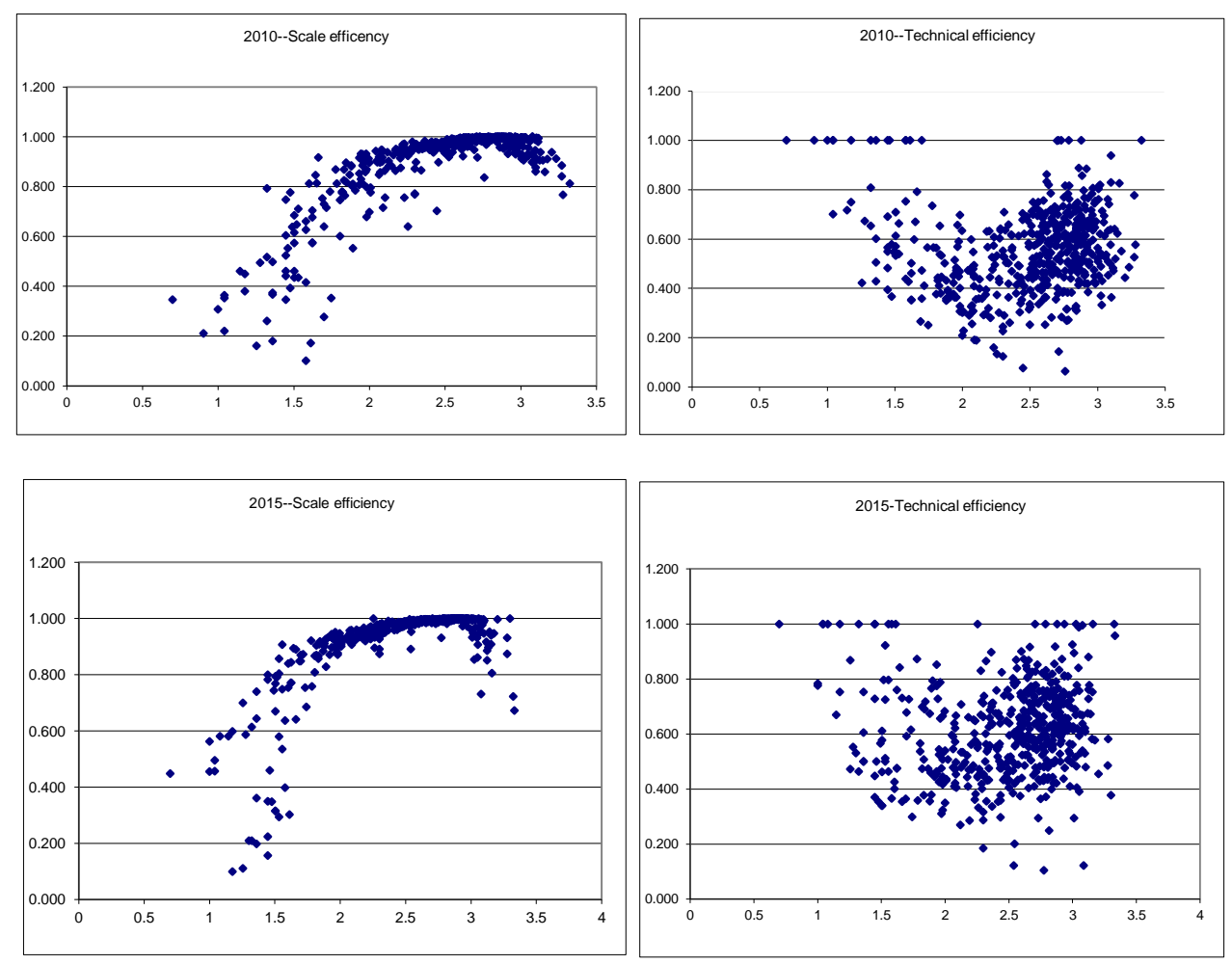
JTA

28.1

As can be observed, a U-shaped relationship between technical efficiency and size is obtained in all cases, supporting the findings by De Jorge and Suárez (2014). As can be observed in Table 4, the highest scores of technically efficient hotels (with a score not lower than 0.9) appear in hotels belonging to the first and fourth quartiles. This result is confirmed in Figure 2. As mentioned below, small hotels commonly offer a more reduced number of services, making management easier. Following De Jorge y Suárez (2014) this may be a consequence of a higher level of quality in the making of internal decisions or in the organization of the production process in smaller hotels. Furthermore, it is striking that the variability of technical and scale efficiencies calculated for small hotels are higher than the rest of hotels. This could be due to hotels not belonging to hotel chains presenting greater heterogeneity in management methods. In the case of large hotels, the high levels of technical efficiency may be explained by the fact that most of them belong to hotel chains, with standardized management and internal control systems, and more intense knowledge accumulation. De Jorge and Suárez (2014) propose that when it reaches a higher level size change the behavior and it may be due to a business strategy.

Regarding scale efficiency, the results are as expected, i.e. scale efficiency increases with hotel size. Large hotels seem to produce close to the optimal scale. However, in the case of the largest hotels, belonging to the fourth quartile, there is a slight decrease in this indicator as observed in Table 4 and Figure 2. This could suggest the presence of decreasing returns of scale for the largest hotels. Indeed, coordination problems in quite large firms might lead to a reduction in scale efficiency.

In a multi-product context, the analysis of the influence of size on efficiency indicators is presented in Table 59. Again the distribution by quartiles according to size has been used.

Table 5. Multi-product analysis of efficiency by size for years 2010 and 2015.

\begin{tabular}{lcccc}
\hline Size & Hotels & $\begin{array}{c}\text { Efficient hotels } \\
\text { VRS } \geq 0.9\end{array}$ & $\begin{array}{c}\text { Average } \\
\text { technical } \\
\text { efficiency }\end{array}$ & $\begin{array}{c}\text { Average scale } \\
\text { efficiency }\end{array}$ \\
\hline 2010 & & & & \\
\hline $0-466$ & 29 & 17 & $0.868(0.157)$ & $0.934(0.091)$ \\
$467-700$ & 30 & 14 & $0.862(0.120)$ & $0.976(0.023)$ \\
$701-914$ & 26 & 16 & $0.910(0.102)$ & $0.974(0.049)$ \\
$>914$ & 28 & 14 & $0.880(0.123)$ & $0.971(0.042)$ \\
\hline 2015 & & & & \\
\hline $0-417$ & 45 & 22 & $0.856(0.146)$ & $0.908(0.129)$ \\
$418-603$ & 45 & 17 & $0.827(0.144)$ & $0.978(0.024)$ \\
$604-850$ & 46 & 19 & $0.855(0.128)$ & $0.976(0.037)$ \\
$>850$ & 44 & 19 & $0.841(0.150)$ & $0.939(0.098)$ \\
\hline
\end{tabular}

Note: standard deviation of indicators appears in brackets. As an illustrative goal, a threshold of 0.9 is taken to define technically efficient hotels.

The results for 2010 show that hotels belonging to the third and the fourth quartiles present higher technical efficiency than those belonging to the first and the second quartiles. Note that hotels considered in the multi-product analysis are large hotels offering five accommodation regimes. In this way, this result can be consistent with those obtained in a single-product approach where a U-shaped relationship was suggested. These hotels would be located in the increasing leg of the U-shaped curve. In the case of 2015, noticeable differences are not observed according to hotel size. In fact, when the number of technically efficient hotels is analyzed, it can be observed that it is not sensitive to hotel size for either year 
Regarding scale efficiency, the pattern is similar to that obtained for the size singleproduct analysis, i.e. a hump-shaped behavior. As mentioned before, multi-product approach restricts the analysis to large hotels offering the five outputs. As a consequence, the decreasing in scale efficiency appears early, in the third quartile of the distribution of hotels by size.

A second determinant analyzed in this research is the hotel category, measured as the number of stars. Similar to size, previous evidence is not clear on the relevance of category for technical efficiency. Assaf and Agbola (2011) estimate an increasing relationship between technical efficiency and category for a sample of Australian hotels. By contrast, Oliveira, Pedro and Marques (2013) do not found a relationship between number of stars and efficiency for the hotels in the Algarve. Whereas, Corne (2015) obtains that hotels with low category reach highest technical efficiency for a sample of French hotels. More recently, Arbelo-Pérez et al (2017) found that quality has a negative impact on cost efficiency and a positive one on profit efficiency for a sample of Spanish hotels.

In a single-product perspective, the results for the relationship between efficiency and hotel category for the case of the Canary Islands are presented in Table 6. As can be observed, a high number of technically efficient hotels appears in the 2-star category in most cases. Moreover the percentage of efficient 2-star hotels over all 2-star hotels is the highest. This result is confirmed by the average technical efficiency indicator supporting findings by Corne (2015) and Arbelo-Pérez et al (2017). In the case of Canary Islands, 2star hotels offer a reduced number of low-quality services. As mentioned above in the analysis of the size variable, this makes management easier10

Table 6. Single-product analysis. Single-product analysis of efficiency by category for 2010 and 2015.

\begin{tabular}{lcccc}
\hline Category & Hotels & $\begin{array}{c}\text { Efficient hotels } \\
\text { VRS } \geq 0.9\end{array}$ & $\begin{array}{c}\text { Average } \\
\text { technical } \\
\text { efficiency }\end{array}$ & $\begin{array}{c}\text { Average scale } \\
\text { efficiency }\end{array}$ \\
\hline 2010 & 71 & & & \\
\hline 2 stars & 161 & 14 & $0.618(0.223)$ & $0.643(0.248)$ \\
3 stars & 229 & 3 & $0.523(0.161)$ & $0.918(0.123)$ \\
4 stars & 41 & 4 & $0.573(0.153)$ & $0.962(0.061)$ \\
5 stars & 76 & 0 & $0.430(0.126)$ & $0.963(0.068)$ \\
\hline 2015 & 162 & & & \\
\hline 2 stars & 237 & 9 & $0.618(0.204)$ & $0.729(0.254)$ \\
3 stars & 44 & 8 & $0.612(0.172)$ & $0.945(0.104)$ \\
4 stars & 0 & $0.626(0.149)$ & $0.974(0.063)$ \\
5 stars & 0 & $0.493(0.099)$ & $0.978(0.037)$ \\
\hline
\end{tabular}

Note: standard deviation of indicators appears in brackets. As an illustrative goal, a threshold of 0.9 is taken to define technically efficient hotels.

Although 4-star hotels are the most numerous in the sample, the percentage of efficient 4-star hotels is very low (below 7\%). It is also surprising that there are no 5 -star hotels with VRS greater than 0.9. Also average technical efficiency of 4 and 5-star hotels is lower than that for the rest of hotels. This can be explained by recognizing that highest levels of quality require more personalized services, i.e. they are more labor intensive. From ISTAC data, it can be calculated that beds/labor ratio is 3.7 for 5 -star hotels, 6.3 for 4-star hotels, 9.9 for 3-star hotels, and 12.4 for 2-star hotels. Results suggest that providing quality and a great number of services in the hotel industry seems to be costly in terms of technical efficiency. This finding is consistent with those from Corne (2015). This author found that budget hotels are more technically efficient than other categories for the case study of the French hospitality sector. As for Arbelo-Pérez et al (2017), they estimated a lower level of cost efficiency for Spanish hotels with higher levels of quality. 
Regarding the scale efficiency indicator, we obtain the highest scores for 4-star and 5-star hotels (above 0.95) and the lowest score for 2-star hotels (about 0.7) in all cases. Thus, it seems that the highest quality hotels are producing close to the optimal scale. This finding suggests that 4 and 5-star hotels appear to be compensating lower technical efficiency by higher scale efficiency. For the case of 4 and 5-star hotels, it can reveal the existence of a management strategy of offering costly and high quality but producing close to the optimal scale.

Table 7 shows the results of efficiency depending on hotel category for the multiproduct approach. Again, 5-star hotels show the lowest levels of technical efficiency. As mentioned above, 5-star hotels offer the highest levels of quality through more personalized services, i.e. they are more labor-intensive. Note that in the case of 2 -star hotels, it is irrelevant because of the reduced number of the 2-star hotels offering the five regimes. With respect to scale efficiency, as in the single-product analysis, 4-star hotels seem to produce quite close to the optimal scale.

Table 7. Multi-product analysis of efficiency by category for 2010 and 2015.

\begin{tabular}{|c|c|c|c|c|}
\hline Category & Hotels & $\begin{array}{l}\text { Efficient hotels } \\
\quad \text { VRS } \geq 0.9\end{array}$ & $\begin{array}{l}\text { Average } \\
\text { technical } \\
\text { efficiency }\end{array}$ & $\begin{array}{l}\text { Average scale } \\
\text { efficiency }\end{array}$ \\
\hline \multicolumn{5}{|l|}{2010} \\
\hline 2 stars & 1 & 1 & 1 & 0.842 \\
\hline 3 stars & 21 & 14 & $0.908(0.128)$ & $0.975(0.052)$ \\
\hline 4 stars & 70 & 39 & $0.890(0.121)$ & $0.970(0.050)$ \\
\hline 5 stars & 21 & 7 & $0.808(0.135)$ & $0.936(0.074)$ \\
\hline \multicolumn{5}{|l|}{2015} \\
\hline 2 stars & 3 & 2 & $0.833(0.223)$ & $0.720(0.216)$ \\
\hline 3 stars & 47 & 31 & $0.911(0.155)$ & $0.941(0.099)$ \\
\hline 4 stars & 104 & 34 & $0.824(0.137)$ & $0.970(0.057)$ \\
\hline 5 stars & 26 & 10 & $0.806(0.158)$ & $0.919(0.095)$ \\
\hline
\end{tabular}

Note: standard deviation of indicators appears in brackets. As an illustration, a threshold of 0.9 is taken to define technically efficient hotels.

A third factor analyzed in this research is hotel location. Barros (2005), for a sample of Portuguese hotels, found that location is relevant in the determination of efficiency. In particular, hotels located in the city are more efficient than hotels far from the city. Badunenko et al (2006) confirms the importance of location but only as a minor factor. Finally, Corne (2015) does not find a relationship between technical efficiency and hotel location.

In this paper, the location was analyzed but focusing on the differences between tourist and non-tourist municipalities, in particular, hotels in the islands' capitals11. It must be noted that visitors to hotels located in islands' capitals choose the destination for different reasons to traditional sun-and-sand tourists.

In a single-product context, the results of the analysis of efficiency by type of municipality, i.e. tourist municipality and island capital, are presented in Table 8 for 2010 and 2015. The detailed results by municipalities are presented in Appendix 1. 
Table 8. Analysis of efficiency by type of municipality for 2010 and 2015.

\begin{tabular}{|c|c|c|c|c|c|}
\hline $\begin{array}{c}\text { Type of } \\
\text { municipality }\end{array}$ & Hotels & $\begin{array}{l}\text { Efficient hotels } \\
\quad \text { VRS } \geq 0.9\end{array}$ & $\begin{array}{l}\text { Average technical } \\
\text { efficiency }\end{array}$ & $\begin{array}{l}\text { Average scale } \\
\text { efficiency }\end{array}$ & $\begin{array}{l}\text { sector } \\
\text { efficiency in } \\
\text { the Canary }\end{array}$ \\
\hline \multicolumn{5}{|l|}{2010} & Islands \\
\hline Tourist towns & 372 & 14 & $0.573(0.161)$ & $0.945(0.118)$ & \\
\hline Island capitals & 77 & 2 & $0.461(0.172)$ & $0.789(0.179)$ & \\
\hline \multicolumn{6}{|l|}{2015} \\
\hline Tourist towns & 393 & 21 & $0.630(0.157)$ & $0.961(0.101)$ & 13 \\
\hline Island capitals & 73 & 2 & $0.528(0.163)$ & $0.851(0.181)$ & \\
\hline
\end{tabular}

As can be observed, technical efficiency seems to be greater in hotels located in tourist municipalities than those located in non-tourist municipalities. This can be due to tourist municipalities concentrating most of the hotel supply, and thus presenting highly intense competition12. In other words, competition may be a discipline mechanism increasing technical efficiency in the hotel industry of the Canary Islands. What is more sun-andsand tourists visiting the Canary Islands perceive as close substitutes accommodation in tourist municipalities of the different islands.

To the contrary, we estimate lower technical efficiency in hotels located in the islands' capitals, which can be due to the low degree of competition. As expected, this last result suggests the possible presence of X-inefficiencies when market supply is highly concentrated (Lovell, 1993). Indeed, a business visitor staying in the island capital finds few substitutes in the island and does not consider the possibility of lodging in hotels located in other islands. However, hotel management located in non-tourist municipalities is easier given that they offer a reduced number of service and visitors spend less time inside the establishment. On balance, results suggest that the effect of the low degree of competition is overcoming the influence of an easier hotel management.

Regarding scale efficiency, it is higher for hotels situated in tourist municipalities than for those located in the islands' capitals. From ISTAC data, the average hotel size in tourist zones is about four times higher than accommodation in the islands' capitals, which explains this result.

Location analysis by type of municipalities cannot be carried out in a multi-product framework since the number of hotels is dramatically reduced and results would not be reliable.

\section{Conclusions and implications}

This research focuses on the estimation of technical and scale efficiencies for the Canary Islands' hotel sector. To do this, DEA methods are carried out by recognizing the presence of variable returns to scale. With the objective of obtaining consistent results, two approaches are followed: a single-product and multi-product analysis.

The main findings suggest that hotels in the Canary Islands are not on the efficiency frontier and inputs could be reduced and, as a consequence, they can save on inputs and costs. Also, we follow a simple descriptive analysis exploring three potential determinants of efficiency level: size, quality and location. Firstly, the smallest and the largest hotels achieve the highest levels of technical efficiency. The reduced number of services offered by small hotels may be the underlying reason behind this finding. Besides high levels of technical efficiency calculated for large hotels could be explained by the fact that most of them belong to hotel chains. Hotel chains are characterized by standardized management and internal control systems and also by more intense knowledge accumulation. 
JTA

28.1

With respect to scale efficiency, a positive relationship between size and scale efficiency is found as expected.

Secondly, when efficiency is studied by hotel category, our findings point out that 2star hotels are the most technically efficient. It is noteworthy that 5 -star hotels obtain the lowest levels of efficiency, i.e. highest levels of quality require more personalized services. As a managerial implication, this finding seems to indicate that providing quality and a great number of services is costly in terms of technical efficiency. This conclusion is robust to the approach followed, i.e., a single and a multi-product approach. With respect to scale efficiency, 4 and 5 -star hotels seems to be producing closer to the optimal scale than 2 and 3 -star hotels. This suggests that highest category hotels are compensating the more personalized services with the exploitation of the economies of scale.

Thirdly, with respect to location by municipalities, our research shows that hotels located in tourist municipalities present higher technical efficiency than those situated in the islands' capitals. This may be explained by a higher degree of competition in tourist municipalities, since they contain about $92 \%$ of the beds offered. So competition may be promoting a discipline mechanism in the tourist industry of the Canary Islands. The geographic concentration of economic activities is a strategic issue for improving individual hotel efficiency. In this sense, our findings suggest that public policies promoting the location of hotels in tourist municipalities may improve technical efficiency and competitiveness in the hotel sector.

Summarizing, our results point out that there exists scope for improvement in technical efficiency in the Canary Island hotel sector. They indicate that more effort must be put in input and output management in order to improve efficiency of hotels, particularly in the case of medium-size and/or high category hotels, and/or located in island capitals. However these results must be interpreted with caution. So 4-5 stars hotels offer personalized services where the consumption of inputs is intensive. This strategy cannot be interpreted as totally inefficient, given that it may be focused on market segment with high purchasing power. This trade-off between quality and efficiency must be taken into account by hotel managers in the design of both production policy and marketing strategies.

Finally, hotels located in Canary Islands do seem to be exploiting economies of scale. Their size, four times greater than hotels in Spain as a whole, seems to respond to a right strategy in terms to be operating close to the optimal scale.

\section{References}

Aigner, D.J., Lovell, C.A.K. and Schmidt, P. (1977). Formulation and estimation of stochastic frontier production function models. Journal of Econometrics, 6. 21-37.

Álvarez, R. and Crespi, G. (2003). Determinants of Technical Efficiency in Small Fims. Small Business Economics, 20, 233-244.

Anderson, R.I., Fish, M. and Michello, F. (1999). Measuring efficiency in the Hotel Industry: A stochastic frontier approach. International Journal of Hospitality Management, 18 (1), 45-57.

Arbelo, A., Pérez-Gómez, P. and Arbelo-Pérez, M. (2017). Cost efficiency and its determinants in the hotel industry. Tourism Economics, 23 (5), 1056-1068.

Arbelo-Pérez, M., Arbelo, A. and Pérez-Gómez, P. (2020). Technological Heterogeneity and Hotel Efficiency: A Bayesian Approach, Cornell Hospitality Quarterly, 61 (2), 170-182.

Arbelo-Pérez, M., Arbelo, A. and Pérez-Gómez, P. (2017). Impact of quality on estimations of hotel efficiency, Tourism Management, 61, 200-208.

Assaf, A.G. and Agbola, F.W. (2011). Total productivity in the Australian hotel industry: estimating and bootstrapping Malmquist indices. Tourism Analysis, 16, 295-304.

Assaf, A.G. and Josiassen, A. (2016). Frontier Analysis: A State-of-the-Art Review and MetaAnalysis. Journal of Travel Research, 1-16. 
Assaf. A.G., Barros. C. P. and Josiassen, A. (2010). Hotel Efficiency: a bootstrapped metafrontier approach. International Journal of Hospitality Management, 29, 468-475.

Hotel

Assaf, A.G. and Tsionas, M. (2018). Measuring hotel performance: Toward more rigorous evidence in both scope and methods. Tourism Management, 69, 69-87.

Badunenko, O., Fritsch, M. and Stephan, A. (2006). What determines the technical efficiency of a firm? The importance of industry. location. and Size. Working Paper 33/2006. Friedrich Schiller Universität Jena.

Banker, R.D. (1993). Maximum Likelihood Consistency and Data Envelopment Analysis. Management Science, 39, 1265-1273.

Banker, R.D., Charnes, A. and Cooper, W. (1984). Some models for estimating technical and scale inefficiencies in data envelopment analysis. Management Science, 30, 1078-1092.

Barros, C. P. (2004). A stochastic cost frontier in the Portuguese hotel industry, Tourism Economics, $10(2), 177-192$.

Barros, C.P. (2005). Measuring efficiency in the hotel sector. Annals of Tourism Research, 32 (2), 456-477.

Barros, C.P. and Dieke, P. (2008). Technical efficiency of African hotels. International Journal of Hospitality Management, 27, 438-447.

Barros, C.P. and Mascarenhas, M.J. (2005). Technical and allocative efficiency in a chain of small hotels. Hospitality Management, 24, 415-436.

Beeson, P.E. and Husted, S. (1989). Patterns and determinants of productive efficiency in state manufacturing. Journal of Regional Science, 29 (1), 15-28.

Benito, B., Solana, J. and P. López (2014). Determinants of Spanish regions' tourism performance: a two-stage, double-bootstrap data envelopment analysis. Tourism Economics, 20 (5), 987-1012.

Bernini, C. and Guizzardi, A. (2010). Internal and locational factors affecting hotel industry efficiency: evidence from Italian business corporations. Tourism Economics, 16 (4), 883-913.

Blake, A., Sinclair, M. T. and Campos, J.A. (2006). Tourism productivity. Evidence from the United Kingdom. Annals of Tourism Research, 33 (4), 1099-1120.

Bottasso, A. and Sembenelli, A. (2004). Does ownership affect firms' efficiency? Panel Data Evidence on Italy. Empirical Economics, 29 (4), 769-786.

Caves, R.E. and Barton, D.R. (1990). Efficiency in US manufacturing industries. Cambridge: MIT Press.

Charnes, A., Cooper, W., and Rhodes, E. (1978). Measuring Efficiency of Decision Making Units. European Journal of Operational Research, 2, 429-444.

Chen, C.F. (2007). Applying the stochastic frontier approach to measure hotel managerial efficiency in Taiwan. Tourism Management, 28, 696-702.

Chen, C. F. and Soo, K. T. (2007). Cost structure and productivity growth of the Taiwanese international tourist hotels. Tourism Management, 28, 1400-1407.

Chiang, W., Tsai, H. and Wang, L. (2004). A DEA Evaluation of Taipei Hotels. Annals of Tourism Research, 31, 712-715.

Coelli, T. (1996). A guide to DEAP version 2.1: a data envelopment analysis (computer program). Working paper 96/08. Centre for Efficiency and Productivity Analysis.

Cooper, W.W., Seiford, L.M. and Tone, K. (1999). Data Envelopment Analysis. A Comprehensive Text with Models Application. Norwell, Mass.: Kluwer Academic Publisher.

Corne, A. (2015). Benchmarking and tourism efficiency in France. Tourism Management, 51, 91-95.

De Jorge, J. and Suárez, C. (2014). Productivity, efficiency and its determinant factors in hotels. The Service Industries Journal, 34 (4), 354-372.

Debreu, G. (1951). The Coefficient of Resource Utilization. Econometrica, 19(3), 273-292.

Deng, Y., Veiga, H. and Wiper, M. P. (2019). Efficiency evaluation of hotel chains: a Spanish case study. SERIES, 10(2), 115-139.

Duro, J.A. (2016). Seasonality of hotel demand in the main Spanish provinces: Measurements and decomposition exercises. Tourism Management, 52, 52-6. 
EXCELTUR \& Gobierno de Canarias (2018). Estudio de Impacto Económico del Turismo:

28.1 IMPACTUR Canarias $2017 . \quad$ URL: https://www.exceltur.or

16 Statistical Society, 120, 253-290.

Fernández, M.A. and Becerra, R. (2015). An Analysis of Spanish Hotel Efficiency. Cornell Hospitality Quarterly, 56 (3), 248-257.

González, M., Martín, R. and Gulliani, A.C. (2015). Evaluating the Efficiency Progress with Technology in a Spanish hotel chain. Revista de Administraçao de Empresas, 55 (5), 551-562.

Gumbau-Albert, M. and Maudos, J. (2002). The determinants of efficiency: the case of the Spanish industry. Applied Economics, 34 (15).

Heshmati, A. (2003). Productivity Growth, Efficiency and Outsourcing in Manufacturing and Service Industries. Journal of Economic Surveys, 17 (1), 79-112.

Hwang, S.N. and Chang, T.Y. (2003). Using data envelopment analysis to measure hotel managerial efficiency change in Taiwan. Tourism Management, 24, 357-369.

ISTAC (2015). Entidades y núcleos turísticos. Cuaderno Cartográfico 2015. Instituto Canario de Estadística. URL: http:/www.gobiernodecanarias.org/istac/galerias/documentos/ C00065A/cuaderno_car tografico_A4_Web.pdf (Accessed on 06.09.2018)

ISTAC (2016a). Encuesta de Alojamiento Turístico. URL: http://www.gobiernodecanarias.org/istac/. (Accessed on 12.09.2017).

ISTAC (2016b): Estadística de Movimientos Turísticos en Fronteras de Canarias. FRONTUR-Canarias. URL: http://www.gobiernodecanarias.org/istac/. (Accessed on 12.09.2017).

Jensen, M. and Meckling, W. (1976). Theory of the Firm: Managerial Behaviour. Agency Costs and Capital Structure. Journal of Financial Economics, 3, 305-360.

Johns, N., Howcroft, B. and Drake, L. (1997). The Use of Data Envelopment Analysis to Monitor Hotel Productivity. Progress in Tourism and Hospitality Research, 3, 119127.

Kim, S. (2011). Factor Determinants of Total Factor Productivity Growth in the Malaysian Hotel Industry: A Stochastic Frontier Approach. Cornell Hospitality Quarterly, 52(1), 3547.

Koopmans, T. (1951). An Analysis of Production as an Efficient Combination of Activities in Koopmans. T. (ed.). Activity analysis of production and allocation. Cowles Commission for Research in Economics. Monograph 13. New York.

Lado-Sestayo, R. and Fernández-Castro, A.S. (2019). The impact of tourist destination on hotel efficiency: A data envelopment analysis approach. European Journal of Operational Research, 272 (2), 674-686.

Lovell, C.A.K. (1993). Production Frontiers and Productive Efficiency, in H.O. Fried, C.A.K. Lovell, and S.S. Schmidt (eds). The Measurement of Productive Efficiency. Techniques and Applications, Oxford. Oxford University Press, 3-67.

Lundvall, K. and Battesse, G.E. (2000). Firm size, age and efficiency: evidence from Kenyan manufacturing firms. Journal of Development Studies, 36 (3), 146-163.

Malerba, F. (1992): Learning by firms and incremental technical change. Economic Journal, 102, 845-859.

Meeusen, W. and Van den Broeck, J. (1977). Efficiency estimation form CobbDouglas production functions with composed error. International Economic Review, 18, 435- 444 . 
Oliveira, R., Pedro, M.I. and Marques, R.C. (2013). Efficiency performance of the Algarbe hotels using a revenue function. International Journal of Hospitality Management, 35, 59-67.

Orazem, P.F. and Vodopivec, M. (2004). Do Market Pressures Induce Economic Efficiency: The Case of Slovenian Manufacturing. 1994-2001. Policy, Research working paper, WPS 3189. Washington, DC: World Bank.

Parte-Esteban, L. and Alberca-Oliver, P. (2015). Determinants of technical efficiency in the Spanish hotel industry: regional and corporate performance factors. Current Issues in Tourism, 18 (4), 391-411.

Pérez, J.V. and Acosta, E. (2007). Cost efficiency of the lodging industry in the tourist destination of Gran Canaria (Spain). Tourism Management, 29, 993-1005.

Pulina, M. and Santoni, V. (2018). A two-stage DEA approach to analyse the efficiency of the hospitality sector. Tourism Economics, 24 (3), 352-365.

Sáez-Fernández, F.J, Jiménez-Hernández, I., and del Sol Ostos-Rey, M. (2020).

Seasonality and Efficiency of the Hotel Industry in the Balearic Islands: Implications for Economic and Environmental Sustainability. Sustainability, 12(9).

Sanjeev, G.M. (2007). Measuring efficiency of the hotel and restaurant sector: the case of India. International Journal of Contemporary Hospitality Management, 19, 378-387.

Shleifer, A. (1998). State versus Private Ownership. Journal of Economic Perspectives, 12 (4), 133-150.

Sigala, M., Airey, D., Jones, P. and Lockwood, A. (2004). ICT paradox lost? A stepwise DEA methodology to evaluate technology investments in tourism setting. Journal of Travel Research, 43, 180-192.

Such, M.J. and Mendieta, L.F. (2013). Size, efficiency and productivity in the Spanish hotel industry-independent properties versus chain-affiliated hotels. Tourism Economics, 19 (4), 801-809.

Walheer, B. and Zhang, L. (2018). Profit Luenberger and Malmquist-Luenberger indexes for multi-activity decision-making units: The case of the star-rated hotel industry in China. Tourism Management, 69, 1-11.

Wang, K.L., Hung, W.T. and Shang, J.K. (2006). Measuring the cost efficiency of international tourist hotels in Taiwan. Tourism Economics, 12 (1), 65-85.

Weng, C.C. and Wang, K.L. (2004). Scale and scope economies of international tourist hotels in Taiwan. Tourism Management, 25, 761-769.

Yang, J. and Zeng, W. (2014). The trade-offs between efficiency and quality in the hospital production: Some evidence from Shenzhen, China. China Economic Review, 31, 166-184. 